\title{
Os Primórdios da Perícia Médica
}

\author{
João Baptista de Oliveira e Costa Juinior \\ Catedrático de Medicina Legal da Faculdade de Direito \\ da Universidade de São Paulo
}

SUMÁRIO: Conceito. Seu aparecimento na Antigüidade. Na Idade Média. No Renascimento. O Código Carolino. Ambrosio Paré e Paulo Zacchia.

Conceito - Para Agostinho José de Souza Lima (Tratado de Medicina Legal - 4a edição 1923 - pág. 48) a perícia médica é "toda a sindicância promovida por autoridade policial ou judiciária, acompanhada de exame que, pela natureza do mesmo, os peritos são ou devem ser médicos". É, pois, o esclarecimento de um fato, mais ou menos duradouro, que pela sua natureza só poderá ser esclarecido por quem possua conhecimentos de medicina, isto é, o médico. Disso decorre que o perito médico é a pessoa entendida e experimentada em temas de medicina, que designado pela autoridade competente, deverá esclarecer um fato de natureza médica mais ou menos duradouro. Cabe-lhe, portanto, o visum et repertum, segundo exigência antiga.

A perícia médico-legal surgiu pela necessidade de solução para casos concretos. A princípio eram vestígios mal percebidos nas legislações primitivas, depois de forma mais evidente, principalmente na Idade Média até definir-se e concretizar-se na Renascença, com a sua instituição oficial no Código Carolino em 1532.

Na Antigüidade - A perícia médico-legal foi tarefa do Estado desde o tempo dos egípcios, conforme consta dos papiros da época, todavia ficou sempre uma dúvida a respeito do aparecimento gradual dos regulamentos durante longo período e da possibilidade de sua origem.

Imhotep, o grão visir, no Egito, chefe da Justiça e médico do rei Zoser, arquiteto da primeira grande pirâmide de Sakkara foi o primeiro a relacionar a medicina com a lei e talvez quem realizou a primeira perícia médico-legal (in R.B.H. Gradwohl-Legal Medicine 1954, pág. 3).

Embora a medicina egípcia estivesse impregnada de magia e divindade, empregando, na cura das doenças, os encantamentos, os amuletos e o exorcismo, alguns historiadores viam traços de perícia nesse país. Assim os sacerdotes médicos verificavam se a morte fora violenta ou natural; a prática do embalsamento exigia a mesma verificação. As leis de Menès, o mais antigo faraó da história, mandavam 
adiar o castigo das mulheres grávidas, excluindo-as das penas aflitivas, o que implicava na intervenção do perito para o diagnóstico da gravidez. Nos crimes de violência sexual, o suspeito era amiarrado sobre o leito em uma das salas do templo, assistia uma hieródula nua, ou apenas com vestes transparentes, dançar ao seu redor, sendo considerado culpado se o "órgão" o traísse, caso contrário inocente.

$\mathrm{Na}$ Caldeia, exercia a função de médico o astrólogo, que analisava o planeta da vítima e do acusado, infeliz este se os signos não fossem concordantes, recorrendo então aos presságios e às flechas divinas.

No tempo das leis sumerianas, um bloco de argila fala do julgamento de um homicida, datado de 1850 a.C.

O Código de Hammurabi, compilação de leis sumerianas prevê penas severas para os casos de erro médico, o que subtendia a prova do erro.

As primeira indicações relativas à perícia médica estão nas leis de Manu, dos indus, onde alguns crimes são comprovados por exames. Aquele que matar um brâmane, cometer adultério, violentar uma virgem, provocar aborto, tocar nos seios de uma mulher casada ou deixar-se tocar por ela, violar uma virgem com os dedos, pratica crime passível de castigos severos (cap. VIII, 358, 364, 367; XI, 87).

As práticas lésbicas de pederastia e a bestialidade eram punidas por lei (cap. VIII, 369, 370; XI, 173, 174); cabia ao brâmane examinar o culpado e a vítima. Antes do exame, porém, ele pronunciava fórmulas médicas, invocando a divindade e usando dizer somente a verdade.

Na Pérsia, o Zend Avesta dá pormenores a respeito dos crimes de sangue e de costumes; classifica os ferimentos em sete categorias, da simples equimose até os ferimentos mortais.

A legislação hebraica, superior às precedentes, porque exigia duas testemunhas para a condenação do suspeito, a responsabilidade das testemunhas e do juiz, a garantia dos tribunais, a publicidade dos debates, a igualdade perante a lei, ausência de meios de tortura, mostrava o sentimento de justiça unido à rigidez do dogma religioso. Nela, os conhecimentos médicos relacionados com vários textos eram aplicados pelo sacerdote, que também exercia a função de médico.

No Deuteronômio - cap. XVII - vols. 8 e 9 - tal função cabia ao sacerdote. Assim "quando foi difícil distinguir entre o sangue e o sangue; uma causa e outra causa; entre a lepra e a lepra, procurai os sacerdotes que o esclarecerão sobre a verdade". O Êxodo e o Levítico contêm preceitos relativos aos costumes. Aquele que "comerciar" com um animal será punido de morte (Êxodo XXII, 19), "Aquele que bater numa mulher grávida e a fizer abortar, pagará uma multa ao marido". "Não se deitará com um homem como se deita com uma mulher; é abominação"; "a mulher não se prostituirá com um animal; 
é abominação". Cite-se o caso de os velhos competentes da cidade analisarem as vestes da vítima nos casos de desvirginamento (Deuteronômio XXII, 13, 14 e 15).

Nos casos de agressão, a vítima e o acusado eram examinados pelos sacrificadores da tribo de Levi. (André Cousin "Essai sur les origines de la Médicine Légale", pág. 13, 1905).

$\mathrm{Na}$ Grécia, os asclepíades examinavam os cadáveres com equimoses e feridas para o diagnóstico da morte natural ou criminosa.

De acordo com as leis de Dracon, todo o processo criminal devia ser instruído pelo archonte. Um médico dava sua opinião depois de ter orado previamente, junto ao altar de Eunénides (chamadas também de Furias, tinham a missão de punir os criminosos quando chegassem ao inferno e eram três: Alecto, Megera e Tisifone). A sentença era proferida pelos Ėfetas, juízes do Tribunal Criminal, instituído por Dracon.

Hipócrates (460 a 370 a.C.) opinou sobre os nascimentos precoces e tardios. Aristóteles (384 a 322 a.C.) estabeleceu o quadragésimo dia, a época da animação do feto e de 80 dias para o feto do sexo feminino, prazos esses seguidos pelos magistrados do Areópago na apreciação do aborto.

No período romano, antes de Justiniano, a primeira determinação relativa à perícia médico-legal foi atribuída a Numa Pompílio, primeiro rei lendário de Roma e que, segundo consta, fora inspirado pela ninfa Egéria quando permitiu a histerectomia nas mulheres mortas e grávidas. As vestais que violassem o véu da castidade eram enterradas vivas depois de examinadas pelas matronas.

Em todos os casos de morte violenta, o cadáver deveria ficar exposto em local público para que qualquer pessoa pudesse opinar a respeito do evento. A Lei das Doze Tábuas, que sucederam às Questões Perpétuas redigidas pelos decenviros estabelecia a avaliação dos danos existentes nas pessoas com ferimentos.

A partir de Constantino (ano 313), sob a influência do cristianismo e principalmente no Código Teodosiano (438) trata a respeito dos problemas relacionados com o casamento.

No século VI, Justiniano determinou aos jurisconsultos que reunissem as legislações esparsas para elaborarem a lei romana: Pandecta, Digesto, Institutos, Novelas, e que, segundo Carlos Magno, mereceu ser denominada a mãe de todas as Ieis humanas. No Digesto está escrito: "Medici non sunt proprie testes, sed magis est judicium quam testimonium".

O Código Justiniano contém muitas disposições relativas à perícia médica, no que se refere ao casamento, à impotência, ao aborto, ao parto, à interdição, às doenças simuladas, etc. 
Entre os romanos já aparece a medicina legal "orientando o legislador na definição do direito positivo e auxiliando o juiz na sua aplicação". (Alcântara Machado, J. "Revista de Criminologia e Medicina Legal - Ano I - n' 1 - julho de 1928, págs. 5 e 6). Parece que as doutrinas biológicas influíram no espírito dos jurisconsultos romanos. Paulo (Dig. 1.5.12) e Ulpiano (Dig. 38.16.3.12) respeitam a autoridade "doctissimi viri Hippocratis". A regulamentação da curatela do "fatuus" e do "furiosus" revela conhecimento de formas da doença mental.

Não existia, porém, uma ordem geral que impusesse ou autorizasse a audiência de peritos médicos nas questões de ordem civil ou penal. Encontra-se, entretanto, no Digesto (25.4.1 e 10) a verificação da prenhez (inspiciendo ventre custodiendoque partu"), justificando a diligência no caso de mulher que se engravida antes da viuvez e no caso de divórcio quando o marido afirmava que engravidara a mulher. Em ambos os casos o exame seria realizado: no primeiro caso, por cinco mulheres livres, as quais poderiam tocar ou palpar o ventre da gestante, sem o seu consentimento; e no segundo caso, após a mulher ser ouvida pelo pretor e se negasse o fato seria examinada por três "obstetrices probatae et artis et fidei".

Em Roma, como em qualquer outro lugar, o exame ou inspeção ocular, afirma Alcântara Machado (ob. cit. pág. 8) "começou por ser um ato pessoal e exclusivo do juiz". É este, primitivamente, quem se certifica, por seus próprios olhos, da materialidade dos fatos atuais, dos resíduos sensiveis dos fatos pregressos". Só mais tarde é que se fez necessário ouvir pessoas entendidas, isto é, a função pericial separou-se da função judicante. Os exames periciais surgiram com mais freqüência, no direito judiciário, quando desapareceu a distinção entre o "jus" e o "judicium", critério dominante antes de Deocleciano. Assim, o processo se desenvolve inicialmente perante aquele que "jus dicit" e depois de estabelecido o direito, perante o juiz que "judicat", nomeado pelas partes e, não havendo acordo, pelo magistrado. Procuravam-no, as partes, entre as pessoas entendidas na matéria. Isso tudo, porém, de forma excepcional, lembrando-se que os agrimensores eram obrigatoriamente nomeados nas questões de terras.

Tornaram-se mais freqüentes ao tempo de Deocleciano e maior a procura de pessoas com conhecimentos técnicos, embora não houvesse norma geral que autorizasse o exame pericial.

Maior era o silêncio quanto ao Processo Penal. A princípio o próprio julgador observava o fato material. Nas Ordenações Manuelinas de 1521, o ofendido era obrigado a mostrar a lesão ao juiz, ou, na ausência deste, a um tabelião. Todavia, apesar disso o juiz delegava tal missão a pessoas entendidas e principalmente a médicos.

Está provado, segundo A. Machado (ob. cit. págs. 11 e 12), que, sem dúvida alguma, a perícia médica figurava na prática forense de 
Roma Imperial, bastando lembrar trechos do laudo de Caio Minucio Valeriano determinado por Heraclides e constante do papiro mencionado por Dareste "e cuja perícia foi assistida por Phaesis e Esuris (decanos da aldeia de Caranis): "Mandou-nos Heraclides verificar o estado de saúde de Mystherion, filho de Cameu, em presença de Petesucho, seu irmão. Declaramos e juramos pela fortuna do imperador Adriano Trajano Augusto: eu, Caio Minucio Valeriano, que, no quinto dia depois de ferido Mystherion, encontrei uma ferida contusa na parte esquerda da cabeça e nela descobri fragmentos de pedra; nós, Phaesis e Esuris, que juntamente com Minucio, vimos a ferida em questão, o que afirmamos sob juramento. Eu, Heraclides, estive presente". Esse laudo pericial está completo: requisição da autoridade, intervenção profissional, juramento prévio, inspeção ocular em presença de testemunhas, descrição da ferida com indicação da sede, da profundidade e da natureza do instrumento vulnerante, redação do auto pelo escrivão.

Na Idade Média - Com a invasão dos povos germânicos e eslavos (alemães, burgondes, góticos, frisões, franco ripuares e salianos) na Europa Ocidental, dominando o Império Romano a "wehrgeld" ou o "preço do sangue" foi o princípio que regulou a legislação dos vencedores. Não se punia em nome de um ideal de justiça ou de moral, mas, para evitar as vinganças continuadas, os legisladores encontraram nas indenizações pecuniárias o meio de evitar a destruição de famílias e tribos. Assim, a lei dos alemães dava pormenores em relação à sede e grau dos ferimentos. A lei sálica continha algumas disposições, tais como:

- "Si quis alterum voluerit occidere et colpos falierit, quid fuerit adprobatum, MMD dinarios qui faciunt solidos LXXX culpabilis judicetur".

- "Si quis alterum in caput placaverit ut cerebrum apareat, et exinde tria ossa, quae super ipso cerebro jacent, exierint, MCC dinários. ".

- "Si inter costas fuerit ant in ventrem ita ut volvus apareat, et usque ad intrania perveniat MCC dinarios, praetermedicatura, solidos $\mathrm{V} "$.

- "Si quis hominem placaverit ita ut sanguis in terra cadat, DC dinarios culpabilis judicetur".

A mulher grávida era também protegida de modo especial:

- "Si quis feminam ingenuam et gravidam trabaterit, si moritur XXVIIIM dinarios. Si vero infantem in utero matris suae occiderit ante quod nomen habeat, quid fuerit adprobatum, IVM dinarios culpabilis judicetur".

De acordo com Mende, Siebolt e Buchner sondavam as feridas e apresentavam relatório ao tribunal. (in A. Cousin - "Essai sur les Origines de la Médicine Légale" - págs. 19 e 20). 
Carlos Magno, no início do século IX, desejando restaurar o Império Romano, procurou dar uma unidade legislativa aos povos subjugados, determinando aos seus bispos que redigissem uma compilação das leis germânicas, dos antigos códigos merovíngeos e do direito romano, espalhassem-na por todos os seus domínios e que ficou conhecida com o nome de Capitulares. Nessas, alguns artigos se referiam à intervenção direta do médico e, recomendando que o juiz se baseasse na opinião dele, principalmente em casos de ferimentos, infanticídio, suicídio, violação, bestialidade e de impotência.

Carlos Magno, nas Capitulares de 805 e 807, afirmava que se iniciara também na arte médica, em sua juventude. Parecia que tudo contribuía para um melhor desenvolvimento da perícia médica, entretanto, o império de Carlos Magno foi dividido, passando a instalar-se o regime feudal, isto é, dos usos e costumes locais predominando no direito. Dest'arte as superstições, o sobrenatural reapareceram com a mística dos germanos, a honra dos franks, sendo as paixões causa de todas as injustiças.

As investigações eram baseadas em provas (Ordalios) como a do fogo, da água fervente e da água fria. Na primeira prova, o acusado para ser considerado inocente deveria carregar nas mãos uma barra de ferro aquecida ao rubro; na segunda, exigia que o acusado retirasse um anel do fundo de um recepiente contendo água fervente; e na terceira, o acusado seria atirado à água com os punhos e os pés atados: se inocente, o corpo afundaria, se culpado boiaria.

Em alguns casos os litigantes deveriam comer certa quantidade de pão e queijo colocados sobre o altar: se o acusado vomitasse convulsivamente era considerado culpado. Prova curiosa era a da cruentação, considerada manifestação do poder divino. O suposto assassino, de uma certa distância do cadáver da vítima, aproximava-se dele, pronunciando-lhe o nome várias vezes, rodeava 2 a 3 vezes o corpo e depois roçava o dedo levemente sobre o ferimento: surgindo sangue era considerado culpado, caso contrário, inocente. Tal prova chegou a ser usada até o século XVII, depois da Idade Medieval. Vários autores discutiram o valor dessa prova: Libavius, em 1594, no seu trabalho "De cruentatione cadaverorum", Blancus em 1547 no seu "Tractatus de incidiis homicidii" e até mesmo Michel Albertus, em 1726, na sua obra "De hemorrhagiis mortuorum et jure cruentationis".

Verifica-se pois que, embora o Direito nessa época medieval se desenvolvesse com lentidão as mulheres entendidas, os médicos e os cirurgiões eram/ convocados, segundo o caso, para opinar sob juramento, ao mesmo tempo que empregavam provas judiciárias pela "disputa", pelo "fogo" ou pela "água".

Assim, no édito de Godefroy de Bouillon (1058-1100), conhecido também como "Assises et bons Usages du Royaume de Jérusalem", havia uma referência às visitas médicas determinadas pela Justiça. 
Lembre-se do julgamento pela peleja, gênero de prova que exigia muito vigor dos pleiteantes . "O "Senhor" mandava que um médico, um cirurgião e um apoticário realizassem os exames necessários. Lê-se, também, num "Recueil d'Etablissementes et Coutumes, Assises et Arrêts de l'Echiquier de Normandie", correspondente ao periodo de 1207 a 1245, entre outras coisas, que quando alguma mulher se queixasse de ter sido violentada, a Justiça exigia o exame realizado por mulheres conhecedoras do assunto.

No ducado da Normandia eram obrigatórios os exames nos casos de homicídio, desvirginamento, de ferimentos, etc.

Registre-se ainda o "Costumes de Paris" ou "Estatuto de São Luiz" de 1260, que suprimiu o duelo judiciário substituindo-o pelas provas, contribuiu para o desenvolvimento da perícia médica. Nessa época, o Direito Canônico influi cada vez mais na jurisdição dos povos. O papa Gregório IX, reunindo as decisões de todos os Concilios, publicou-as sob o nome de Decretais, onde certas questões dependiam de intervenção médica. Para casos de impotência havia a famosa prova do congresso: essas Decretais exigiam exame médico dos órgãos sexuais, bem como a prova da conjunção carnal na presença de testemunhas. $\mathrm{O}$ médico autorizado pelo magistrado examinava o "temperamento e a conformação das partes". Uma matrona, conhecedora e experimentada nessa matéria, exortava o marido e a mulher deitados juntos, inclusive untava as partes genitais com ungüento apropriado, devendo depois relatar fielmente ao médico tudo o que observara. Se o caso não ficasse esclarecido, a matrona era substituída por uma comissão constituída por 3 médicos, 3 cirurgiões e 3 mulheres sábias, que separados do casal apenas por uma cortina deviam verificar "an facta esset emissio, ubi, quid, et quale esset emissum". Além dos casos de impotência eram de verificação médica os casos de bruxaria, casamento, atentados ao pudor e de aborto. Quando, porém, os casos se relacionavam com dogmas religiosos o julgamento era feito por tribunais eclesiásticos. Assim, um decreto de Inocente III, de 1209, determina o exame médico de pessoas feridas. Num caso de ladrão de igreja, ferido com um golpe de enxada, o tribunal indagou se o ferimento era leve "ut peritorum judicio medicorum talis percussio assereretur non fuisse lethalis".

A partir do século XIII até o século XVII a influência da religião na mentalidade social refletia-se nos processos civis e criminais. O Direito Canônico predominava nas regras de separação dos corpos, nos processos contra a bruxaria e nas decisões dos Papas, porque os médicos quase todos eram eclesiásticos que se baseavam nos ensinamentos de Aristóteles, Hipócrates, Galeno e Avicena.

Todavia, no fim do século XII, as Cartas Batentes de Felipe, o Audaz ou o Temerário, de 1278, dão conta das verificações judiciárias por cirurgiões juramentados junto ao rei e aos intendentes de algumas 
cidades "Per dictum Cirurgicorum ad hoc Nobis et Majori et civibus juratorum".

Felipe, o Belo, o rei legista, regulamentou o exercício da cirurgia, dando algumas garantias à perícia quando o exercício da medicina era permitido a quem quer que fosse. O Édito de novembro de 1311 proíbe a atividade cirúrgica àqueles que não tenham sido examinados por cirurgiões juramentados instituídos pelo "Châtelet" ("Antiga Jurisdição em Paris"). Médicos e cirurgiões examinavam pessoas feridas ou mortas encontradas na via pública.

É curioso o exame realizado pelo mestre Henri Tristan em 25/8/1332, que afirma ter examinado o corpo de Tristan Jehannin de Troyes, morto sem qualquer ferimento, tendo concluído pela morte por apoplexia, o qual expurgava pelos ouvidos, narinas e boca.

Há inúmeras perícias desse gênero referidas nas obras especializadas em Medicina Legal. Curiosa, entretanto, é a que está relatada no "Traité des erreurs populaires en Médicine", Lyon 1534, de Laurent Joubert, grão-chanceler da Universidade de Montpellier.

"Nous Marian Teste, Jeanne de Means, Jeanne de la Guigan et Magdeleine da la Lippue", matrones jurées de la Ville de Paris, certifions à tous qu'il appartiendra que la quatorzième de juin 1532, par l'ordonnance de M. Prévost de Paris, nous sommes transportées en la rue de Frépant, oú pend pour enseigne la Pantoufle, oú nous avons vu et visité Henriette Pélicière, jeune fille àgé de quinze ans, sur la plainte faite par elle en justice contre Simon de Bragard, duquel elle a dit avoir etè forcées et déforée. Et le tout vu et visité ou doigt et à l'oeil, nous trouvons qu'elle a: les barres froissés, le haleron démis, la dame du milieu retirée, le ponant débiffé, les toutons devyez, l'enchenart retourné, la babbole abbatuë, l'entrepent riddé, l'arrière-fosse ouverte, le guilboquet fendu, le lippon recroquevillé, le barbidant tout escorché; et le tout vu et visité feuillet, avons trouvé qu'il y avait trace de $\mathrm{V}$.". Assinale-se que Malgaigne tentou traduzir, mas desistiu.

Tais exames demonstravam os fracos conhecimentos anatômicos e o total desconhecimento da fisiologia. Exigia-se, nos relatórios, o interrogatório sobre o estado da vítima, o prognóstico dos ferimentos; de perigo de vida; se a morte era voluntária, criminosa ou provocada por doença. Que valor, porém, teriam tais relatórios sem necrópsias e conhecimentos anatômicos?

Michelet afirma, na sua História da França, que os primeiros anos de século XIV foram um "longo processo". "O fim do processo do Templo foi o começo de vinte outros". Essas tragédias tinham perturbado as imaginações: as penas, os suplícios, eram eles mesmos verdadeiros crimes. Acusações não param: envenenamentos, adultérios, falsidades e principalmente bruxarias. As peças de convicção, 
amuletos, filtros, sapos, gato negro, imagens cravadas de agulhas eram apresentadas aos tribunais. A tortura campeava a larga: cordas, esfriamentos, banquetas, pinças, tenazes, tornos, tripeça ao rubro, a prova de água, o borzeguim, o enxofre derretido sobre o corpo, etc. As penas eram ferozes.

Equiparava-se a sodomia à heresia. Queimava-se o culpado vivo. Assim, Didier Lengarat, de 37 anos, sapateiro em Joinville, acusado de bestialidade é queimado vivo juntamente com uma jumenta no dia 27/10/1604. Do mesmo modo, em 23/08/1609, Pierre Dupin, apoticário, foi queimado com uma vaca; em 8 de maio de 1617 Julien Largereux sofreu a mesma pena com uma égua. Muitos outros casos foram registrados em França e em outros países. A fornicação com infiel era considerado caso de bestialidade.

Os processos contra bruxaria e possessão foram numerosos. O número de doentes mentais aumentava sempre. Epidemias estranhas surgiam por toda a parte: dos dançarinos de S. João, do tarantelismo na Itália, dos ladradores, dos flageladores, da possessão das Ursulinas, das convulsionárias de S. Medardo.

Assustado com a presença de tanto demônio na população, Inocente VIII lança em 1484, a bula contra a diabrura. Para a prova da demonopatia, os médicos pesquisavam os "stigmata diaboli" debaixo da língua, dentro dos lábios, dentro do nariz, no pêlo da cabeça, entre os dedos, na unha, no "fundamento" do homem e "natureza" da mulher.

A Idade Média passa e na Renascença a perícia encontra o período favorável para o seu florescimento.

Em 1507, Jean de Schwatzemberg, chanceler do bispo de Bamberg redigiu uma Ordenação para esse príncipe, na qual estabeleceu e regulou a intervenção dos médicos na Justiça e que mais tarde serviu de base para a Constituição de Carlos V

Foi decisiva, para o desenvolvimento da perícia médica, a promulgação da referida Constituição Carolina, na Dieta de Ratis bonne em 1532, como lei do Império Germânico. Há artigos da Constituição Carolina que autorizam a intervenção de médicos e de mulheres, conhecedoras do assunto, e alguns que indicam uma iniciativa inclusive para a prática da autópsia.

Assim: "art. 35 - Se uma jovem é suspeita de estar clandestinamente grávida e de ter matado o produto da concepção, dever-se-á antes de informar que ela tenha sido vista em estado muito aparente de gravidez, e se em seguida essa gravidez tenha diminuído, se ela se tornou pálida e fraca. Se esses sinais e indícios são encontrados de tal modo que se possa suspeitar, convém ir mais longe e fazer com que matronas honestas e experimentadas a examinem secretamente. Se essa visita confirmar a suspeita e não obstante ela não tenha confessado o delito, poderá ser torturada". 
"art. 36 - Quando depois de pouco tempo da morte da criança a mãe não tenha ainda perdido seu leite, poderá ordenhar o leite da mama, e se ele é bom e perfeito, será uma forte evidente presunção para ser torturada. Todavia, como alguns médicos ensinam que pode haver leite por causas naturais mesmo em jovem que jamais tenha se engravidado, se um fato semelhante é invocado, é necessário que as mulheres conhecedoras façam uma rigorosa verificação"

"art. 147 - Se alguém que tiver sido espancado e ferido morre ao cabo de algum tempo de modo que, deixe dúvida e a morte foi ou não ocasionada pelos golpes ou ferimentos, cirurgiões experimentados nessas coisas, verificarão como o morto se comportou depois dos golpes e ferimentos bem como indicarão o tempo de sobrevivência"

"art. 149 - Nos casos supracitados, havendo necessidade de recorrer a exame, à apreciação das lesões e à causa dos ferimentos, o juiz, acompanhado de um ou vários cirurgiões, os quais deverão prestar juramento e proceder diligentemente a inspeção do cadáver antes que este seja enterrado e consignar exatamente todos os ferimentos, golpes, marcas. ".

Foi considerável a influência da Constituição Carolina para o desenvolvimento da Perícia Médica, principalmente porque ela foi promulgada em plena Renascença, numa época em que florescia a Anatomia com Ingrassies, Eustáquio, Falope, Varole, Arantius e sobretudo com Vesale, que em $1543 \mathrm{fez}$ a primeira descrição do corpo humano após observação pessoal.

Deve-se, portanto, ressaltar que foi na Alemanha em boa hora que se deu importância capital à função do perito, confiando-se esse papel a homens de moralidade e instrução reconhecidas e agregados às cortes de Justiça.

As decisões dos peritos, principalmente quando se relacionasse com assuntos importantes eram submetidas às luzes das universidades que os discutiam e comentavam. Criaram as cadeiras de Medicina Legal nas universidades alemãs no princípio do século XVII, na França criaram-na no III ano da República.

Assim, em 1603, Henrique IV encarrega seu primeiro médico Jean de la Revière de nomear em comissão "em todas as boas cidades de jurisdição do Reino, duas pessoas na arte de medicina e cirurgia, da melhor reputação, probidade e experiência, incumbidas de realizar exames e relatórios para a Justiça. Com exceção, para os juramentados do "Chatelet" que o rei mesmo os nomeava.

Bem mais tarde, em agosto de 1670, uma ordenação criminal de Saint Germain - en - Laye, complemento do Codigo Luiz, confirma e regulariza um estado de coisas de fato já existente, tais como se pode verificar: 
"Título V - Das relações dos médicos e dos cirurgiōes".

"art. 1 - As pessoas feridas poderão ser examinadas pelos médicos e cirurgiões que darão sua opinião verdadeira; isso será feito naqueles que morreram, e o relatório juntado ao processo".

"art. 2 - Poderão contudo os juízes ordenar uma segunda visita por médicos e cirurgiões nomeados de ofício, os quais prestarão juramento, do qual será expedido ato, e depois da visita farão a respeito do assunto um relatório que assinarão, que será enviado ao cartório e juntado ao processo.

"art. 3 - Exige-se que todos relatórios ordenados pela Justiça sejam assistidos ao menos por um dos cirurgiões indicados pelo nosso primeiro médico, e nos lugares onde há a omissão dessa indicação é caso de nulidade do relatório".

"Título VI - Das sentenças, julgamentos e arrestos".

"art. 23 - Se alguma mulher, antes ou depois de ter sido condenada à morte, estiver ou declarar estar grávida (os juízes ordenarão que ela seja examinada por matronas que serão nomeadas de ofícios, e que farão seu relatório na forma prescrita para os peritos. E se ela se achar grávída, a execução será adiada para depois do parto juntado ao processo".

Em 1692, um regulamento dispôs sobre a forma dos relatórios. Determina que no inverno os cadáveres sejam abertos só após 24 horas, ao passo que no verão depois de 12 horas. Exige ainda que conste no relatório o número, a localização, direção, profundidade, comprimento, largura e letalidade (pravidade) dos ferimentos; indique as armas, os instrumentos que os produziram; se o ferido ficou aleijado, mutilado; quando deverá ocorrer a cura".

Blégny, em 1684, publicou uma pequena obra "Doutrina des Raports", no qual se pode anotar alguns ensinamentos. É dessa obra: "Os cirurgióes juramentados foram instituídos para previnir os abusos que poderiam ser cometidos se todos os cirurgiões pudessem fazer relatórios válidos na Justiça; pois a incapacidade de alguns e a infidelidade de outros seriam poderosos obstáculos para a Verdade".

Haveria dois peritos juramentados em cada cidade, que possuísse cortes, bispos, arcebispos, "Présidial" (antigo tribunal da França) e um em cada um dos outros burgos ou lugares. Eles teriam o título de conselheiros médicos ordinários do rei, cirurgiōes juramentados. Os juízes não poderiam receber qualquer relatório sem a assinatura deles.

Os relatórios eram de três espécies:

1) Relatório denunciativo - realizado por simples requisição das partes por todos os cirurgiões que tivessem prestado juramento;

2) Relatório provisório ou realizado por ordem do juiz. 
3) Relatório misto ou acertadas pela simples requisição das partes e só realizado por peritos juramentados.

Além desses casos havia ainda dois documentos judiciârios: os "certificados" e as "avaliações". No primeiro caso o "certificado" eclesiástico, para fins eclesiásticos - dispensa de votos conventuais e monásticos; o "certificado" político - para verificar a invalidez dos soldados e dos serviçais das casas reais, e o "certificado" jurídico para adiar um processo, por ter uma das partes adoecido.

No segundo caso "avaliações" são a estimativa do preço do tratamento e operações quando o preço era contestado pelo doente. Com a evolução ocorrida até então, o aparecimento da Medicina Legal se deu em 1575, no período denominado moderno e, ainda assim, por uma forma incipiente, com Ambroise Paré, cognominado por Lacassagneo, pai da Medicina Legal, que publicou o seu "Tratado dos Relatórios e do Meio de Embalsamar" (27. Livro), na verdade um pequeno trabalho, de 24 páginas das suas Obras Ciompletas (reeditadas em 1840-41 Paris).

Apesar de tudo, são as primeiras páginas escritas por um mestre.

Entre os exemplos de relatório pode-se destacar o seguinte, elaborado por Ambroise Paré:

"Para isso, por determinação do senhor o grande Preboste de Hostel, transportei-me para a rua Santo Honorato, na casa do $\mathrm{Sr}$. onde examinei a moça chamada Margarida, deitada no leito, com febre alta, convulsões e hemorragia pela sua natureza, motivada por uma ferida sofrida no baixo ventre, situada três dedos abaixo do umbigo, para direita, a qual penetrou no interior, tendo ferido a matriz, por meio do qual ocorreu o parto antes do tempo previsto, de uma criança do sexo masculino, morta, bem formada em todos os seus membros, tendo a criança também recebido o golpe na cabeça, penetrando inclusive na própria substância do cérebro. E por isso a dita moça em breve morrerá, sobretudo que certifico é verdade, .etc.".

Ambroise Paré refere-se às dificuldades do prognóstico das feridas; estuda os sinais clínicos dos principais traumatismos, (sinais do cérebro atingido, do pulmão vulnerado, das lesões do coração, veia cava, da grande artéria, da medula, do estômago, do baço, dos rins, da bexiga), da impotência, do desvirginamento, etc.

Ponto de referência para o aperfeiçoamento da perícia médica é a obra de Baptista Codronchi, publicada em 1597 sob o título "Methodus testificandi, in quibusdam casibus medicis ablatis" Nela, o autor estuda as principais questões judiciárias relacionadas com as doenças, feridas, morte súbita, envenenamento, puberdade, virgindade, gravidez e parto. Apresenta, também, no final do livro, modelos de relatórios sobre casos ocorridos no exercício de sua profissão e que ele inicia, com muita modéstia, da seguinte forma: "Eu, Codronchi, o mais humilde dos médicos e filósofos de Imola. ". 
Assinale-se ainda que Fortinatus Fidelis, médico de São Felipe de Agirone, publica em 1602, "De relationibus medicorum in quibusdam ea omnia, quae in forensibus, ac publicis causis, Medici referre solent plenissme traduntur".

A obra mais importante, que marcou época, é a do italiano Paulo Zacchia, publicada em 7 livros, de 1621 a 1658 sob o título de "Quaestiones, Medico Legales". O ilustre autor era médico do Papa e perito da Rota Romana, tendo recebido por essa obra os elogios dos médicos e teólogos contemporâneos e seu prestígio perdurou por quase dois séculos, podendo ainda ser consultado, na atualidade, com real proveito. $\mathbf{E}$ um trabalho de erudição cujas questões foram tratadas à luz do Direito Canônico. A casuística, última parte (hoje $3^{\circ}$ volume), corresponde aos casos estudados e acompanhados de relatórios das perícias feitas para o Tribunal Eclesiástico. Assim foram estudados: o dever conjugal, milagres, estigmas da demonopatia, jejunal, quaresma, ofícios divinos, claustro monacal, dando ao relatório médico uma importância considerável. Não era, pois, de se estranhar que esses fatos tratados com todo o cuidado pelo ilustre médico de Inocêncio IV, em uma época em que o Direito Canônico exercia grande influência nas jurisdições.

Sua obra, reeditada muitas vezes, aparece dividida em três tomos, na $1^{\text {a }}$ edição Venetiis, 1737 - Tipographia Bonifacii Viezzeri.

No I volume trata de questões sobre diversas fases da vida da infância até a senilidade; sobre o parto (7,8,9, e 10 meses), sinais de feto vivo, aborto, etc.; sobre a prenhez, superfetação e mola; causa de morte no parto; das semelhanças e dissemelhanças dos recém-nascidos; das doenças mentais sob o título de demências; dos venenos e envenenamentos; das doenças relacionadas com o sexo; das simulações; da peste e do contágio; dos milagres, da virgindade e estupro; dos jejuns e quadragésima; dos ferimentos; das debilidades e mutilações de membros; do ar, da água e dos licores. No II volume cuida dos erros médicos e das leis que os pune; das penas e dos castigos; da precedência entre os médicos; dos prodígios e dos monstros; dos ofícios divinos; do dever conjugal; dos estigmas "magorum"; de diversas perturbações ("irregularitate"); das medicações; da animação dos fetos humanos; do feto "exsecto" e do parto cesariano; da impotência coeundi e generandi; dos benefícios da resignação; das doenças impeditivas da eucaristia; dissolução matrimonial, divórcio; do sêmen feminino; da primogenitura. No III volume - apresenta grande elenco de decisões da Santa Rota Romana.

Depois da obra do grande mestre (outros trabalhos surgiram. "Os sinais da virgindade" de Severin Pineau, em 1598; "A crítica feita ao 'congresso' na verificação da impotência”, de Vincent Tagereau, em 1611 e o "Estudo da 'docemasia hidrostática de Galeno'" por Bartholin, em 1663, e aplicada pela primeira vez por João Schreyer, da Silésia. 
Registrem-se ainda os tratados de Gendry, em Angers; de Blegnò, em Lion (1684) e principalmente "L'Art des Rapports", publicada por Devaux, em 1708.

A Renascença e o século XVII marcam então o início do período científico da perícia.

A Alemanha foi, portanto, beneficiada com as disposições da Constituição Carolina, pela unidade do procedimento criminal e pela excelente organização da medicina judiciária.

Welsch (1660) analisa a letalidade dos ferimentos e afirma sobre a utilidade da autópsia no "Rationale vulnerum lethalium judicium".

Bohn (1689) cuida com mais profundidade do mesmo assunto em "De renunciatione vulnerum".

No século XVIII Michel Bernhardt Valentim publica várias questões médico-judiciárias apreciadas pelos tribunais alemães (e discutidas nas universidades, num livro intitulado "Pandectae medico legales".

Seguiram-se depois os trabalhos, no mesmo sentido, de Zittmann (1706); Alberti (1725); Loew (1725); Richter (1731), que levavam em conta as decisões das universidades e dos cursos eclesiásticos e civis.

Muitas obras foram publicadas depois, em diversos países, destacando a importância da perícia e do ensino da Medicina Legal.

\section{Bibliografia}

ALCANTARA Machado D'Oliveira, J. de "O exame pericial no dineito romano" - in Revista de Criminologia e Medicina Legal - Ano I - Num. 1 - julho 1928 - pág. 5/12. ALMEIDA Júnior, A. e Costa Júnior, J.B. de Oliveira e - "Licões de Medicina Legal" $16^{\text {n }}$ edição'- 1979 págs. 13/15.

BORRI, L. - in "Trattato di Medicina Legale" de Borri, L. - Cevidalli, A. - Leoncini, F. - Vol. Primo - 1922 - págs. 1/11.

CARrara, M. - Romanese, Canuto, G. e Torre C. "Manuale di Medicina Legale" Vol. I - 1937 - págs. 24/30.

CASPER "Traité de Médicine Legịle" - Trad. francesa de Baillière - 1881 - págs. 15/20.

COUSIN, André - "Essai Sur les Origines de la Médicine Légale" - Paris Imprimerier de la Faculté de Médicine - 1905.

FÃVERO, Flaminio - "Medicina Legal" - 10 volume - 9 edição — págs. 16/17.

GRADWOH, R.B.H. - "Legal Medicine" - St. Louis - 1954 - págs. 1/11.

LACASSAGNE, A. - "Compendio di Medina Legale" - Trad. italiana pelo Dr. Mario Carrara - 1909 - págs. 1/12.

PARE, Ambroise - "Oeuvres Completes D'Ambroise Pare" - Tome Troisieme - J.F. Malgaigne - Paris - 1841 - págs. 651/.75.

SEDILLOT, C. "Manual Completo de Medicina Legal" - Trad. Antonio José de Lima Leitão - 1855 - Tomo I.

SOUZA Lima, Agostinho José de — "Tratado de Medicina Légal" - 4 edição 1923 págs. 22/29 e pág. 48.

ZACCHIA, Paulo - "Quaestiones Medico-Legales" Tomi Tres - Editio prima - Venetá Venetiis, MDCCXXXVII.

ZIINO, G. - “Compendio di Medicina Legale" - Libro Primo - 1882 págs. 1/3. 